\title{
Slowing of mask-triggered inhibition in the elderly
}

\section{Rolf Verleger*}

Department of Neurology, University of Lübeck, Lübeck, Germany

*Correspondence: rolf.verleger@neuro.uni-luebeck.de

\section{A commentary on}

Inhibitory motor control in old age: evidence for de-automatization?

by Maylor, E. A., Birak, K. S., and Schlaghecken (2011). Front. Psychol. 2:132. doi: 10.3389/ fpsyg.2011.00132

Maylor et al.'s (2011) study combines the Simon effect, a well-investigated manipulation, with the masked-priming technique. This is an original idea, and the study was competently performed. This interesting approach provides new evidence about changes of response control in old age.

The impact of this paper might be further improved if alternative accounts of inverse priming (viz. of the "negative compatibility effect," NCE) were considered. In the following, I will point to some problems in the authors' conception of this effect and will argue that an alternative account of inverse priming might provide a more coherent view on the highly interesting results reported in this study.

According to Maylor et al.'s (2011) Introduction, reflecting the extensive work of this group on the NCE, inverse priming is due to "automatic inhibition" of prime activation, reflecting "low-level" processing in the motor system, independent of "high-level" control. Such highlevel control, involving pre-frontal areas, is assumed to be restricted to consciously perceived incongruencies between stimuli and responses. Indeed, therefore, in young adults the Simon effect is independent of the NCE.

Casting doubt on this neat distinction, Boy et al. (2010) reported interactions between the NCE and the consciously perceived incongruency of flanking stimuli and the required response. This prompted Maylor et al. (2011) to constrain the assumed independence to cases when the two conflicts do not "come from the same domain" (Footnote in their Introduction): shape information (NCE) may interact with shape information (flankers) but does not interact with location information (Simon). If so, the distinction between low-level and high-level might become unnecessary.

Direct evidence against the notion that unconsciously perceived primes are processed without higher-level pre-frontal involvement derives from the phenomena reported by Mattler (2003, 2005, 2007) where masked cue-like primes, like the ones used by the present authors, affected the non-motor decisions induced by a following cue. Indeed, using Mattler's task, Lau and Passingham (2007) found pre-frontal activation induced by inverse priming, different from what the "low-level" account predicts.

The major, important result of Maylor et al.'s (2011) paper is that older adults' NCEs may attain the same magnitude as in young adults, but at much increased latencies (where the NCE even appears to become larger than in the young). This interesting result is actually hard to explain in terms of the "low-level" conception: how can some automatically induced process be delayed by hundreds of ms and then finally appear in full size? Maylor et al. refer to this as "de-automatization." This might account for disappearance of the process. But why should this process appear in the final end? Maylor et al. argue that the process is then consciously implemented by the elderly. Why should it be: is it of any use? And if it may be consciously implemented by the elderly, why not by the young?

Is there a more parsimonious account? It may be noted that, in Maylor et al.'s (2011) "automatic inhibition" account, the mask does not play any role (and is therefore hardly mentioned in the Introduction) except "to reduce prime visibility" (as noted in Methods). The role of the mask is the point of departure of the most interesting alternative account, proposed by Jaśkowski (2007) which is unfortunately only briefly mentioned and immediately dismissed in Maylor et al.'s (2011) Introduction (see also Boy et al., 2008; Jaśkowski, 2008; Jaśkowski et al., 2008): inverse priming is due to the mask. The mask indicates to participants that prime-induced activation was too early. This is why the mask induces inhibition. This proposal was recently integrated by Klauer and Dittrich (2010) with their results from verbal priming to say that the critical factor is participants' segmentation of events into "evaluation windows": the mask is used by participants as a temporal marker to terminate the premature window opened by the prime and, by this, to cancel activation induced by the prime.

This hypothesis can account for the above-mentioned difficulties: the NCE interacts with the flanker effect because both the flankers and the prime induce premature activation which has to be canceled. Prefrontal activation may arise because perceiving the mask as a stimulus for adjusting temporal orientation may involve behavioral control. Furthermore, the hypothesis may be applied to the present data to say: the closing and opening of evaluation windows is precise in the young and more sluggish in the old adults. Therefore, mask-induced inhibition is too slow in the elderly to become effective when responses are sufficiently fast. Thus, rather than for de-automatization, the present data may be evidence for sluggish temporal structuring in the elderly.

\section{ACKNOWLEDGMENTS}

When writing this article, the author was funded by German Research Foundation (DFG, Ve110/15-1) as participant at the package proposal "Neuro-cognitive mechanisms of conscious and unconscious visual perception" (www.uni-ulm.de/unbewusst). I owe deep gratitude to my late colleague Piotr Jaśkowski for having shared his insights with me.

\section{REFERENCES}

Boy, F., Clarke, K., and Sumner, P. (2008). Mask stimulus triggers inhibition in subliminal visuomotor priming. Exp. Brain Res. 190, 111-116.

Boy, F., Husain, M., and Sumner, P. (2010). Unconscious inhibition separates two forms of cognitive control. Proc. Natl. Acad. Sci. U.S.A. 107, 11134-11139.

Jaśkowski, P. (2007). The effect of nonmasking distractors on the priming of motor responses. J. Exp. Psychol. Hum. Percept. Perform. 33, 456-468. 
Jaśkowski, P. (2008). The negative compatibility effect with nonmasking flankers: a case for mask-triggered inhibition hypothesis. Conscious. Cogn. 17, 765-777.

Jaśkowski, P., BiaŁuńska, A., Tomanek, M., and Verleger, R. (2008). Mask- and distractor-triggered inhibitory processes in the priming of motor responses: an EEG study. Psychophysiology 45, 70-85.

Klauer, K. C., and Dittrich, K. (2010). From sunshine to double arrows: an evaluation window account of negative compatibility effects. J. Exp. Psychol. Gen. 36, 892-905.

Lau, H. C., and Passingham, R. E. (2007). Unconscious activation of the cognitive control system in the human prefrontal cortex. J. Neurosci. 27, 5805-5811.

Mattler, U. (2003). Priming of mental operations by masked stimuli. Percept. Psychophys. 65, 167-187.

Mattler, U. (2005). Inhibition and decay of motor and nonmotor priming. Percept. Psychophys. 67, 285-300.

Mattler, U. (2007). Inverse target- and cue-priming effects of masked stimuli. J. Exp. Psychol. Hum. Percept. Perform. 33, 83-102.

Maylor, E.A., Birak, K.S., and Schlaghecken, F. (2011). Inhibitory motor control in old age: evidence for de-automatization? Front. Psychol. 2:132. doi: 10.3389/fpsyg.2011.00132
Received: 09 June 2011; accepted: 09 June 2011; published online: 22 June 2011.

Citation: Verleger $R$ (2011) Slowing of mask-triggered inhibition in the elderly. Front. Psychology 2:138. doi: 10.3389/ fpsyg.2011.00138

This article was submitted to Frontiers in Cognition, a specialty of Frontiers in Psychology.

Copyright (c) 2011 Verleger. This is an open-access article subject to a non-exclusive license between the authors and Frontiers Media SA, which permits use, distribution and reproduction in other forums, provided the original authors and source are credited and other Frontiers conditions are complied with. 